\title{
Overexpression of TGF- $\alpha$ and EGFR, a key event in liver carcinogenesis, is induced by hypoxia specifically in hepatocytes
}

\author{
Ido Zambreg ${ }^{1}$, Benjamin Assouline ${ }^{1}$, Chantal Housset ${ }^{2}$ and Eduardo Schiffer ${ }^{1,2 *}$ \\ ${ }^{1}$ Department of Anesthesiology, Geneva University Hospitals, Switzerland \\ ${ }^{2}$ Department of Hepatology, Saint-Antoine Hospital, Sorbonne Université, INSERM, Centre de Recherche Saint-Antoine (CRSA), Assistance Publique-Hôpitaux \\ de Paris (AP-HP), Paris, France
}

\begin{abstract}
Transforming growth factor alpha (TGF- $\alpha$ ) is a mitogenic factor for hepatocyte and a ligand of the epithelial growth factor receptor (EGFR). TGF- $\alpha$ promotes liver carcinogenesis. TGF- $\alpha$ is also overexpressed in regenerative nodules of the cirrhotic liver but the mechanism of this expression is poorly known. Because hypoxia is a feature of cirrhotic livers and hypoxia may induce TGF- $\alpha$ and EGFR expressions, the aim of this study was to determine whether the TGF- $\alpha$ /EGFR pathway is affected by hypoxia in liver cells. Cell isolates were prepared from normal Wistar rats. Liver myofibroblasts were obtained in culture by activation of hepatic stellate cells (HSC), and by outgrowth of portal myofibroblasts from bile duct segments. Hepatocytes, Kupffer cells and liver myofibroblasts in culture were submitted to hypoxia for 4-24 hours. Hypoxia was achieved using a catalytic system, which reduces oxygen concentration to less than $1 \%$ within 30 minutes. The absence of toxicity was verified by lactate dehydrogenase dosing in cell supernatant. Vascular endothelial growth factor (VEGF) served as a hypoxia-inducible control gene. Gene expression was assessed by real-time reverse transcription polymerase chain reaction (RT-PCR). Under normoxia, the expression of TGF- $\alpha$ was significantly higher in hepatocytes than in non-parenchymal liver cells ( 1.7-fold). EGFR transcripts were also more abundant in Hepatocytes than in myofibroblasts ( 3-fold) or in Kupffer cells ( 22-fold). Hypoxia induced an increase in VEGF mRNA to a similar extent in all cell types. By contrast, hypoxia caused an increase in TGF- $\alpha$ transcripts mainly in Hepatocytes (112 \pm 7 vs $32 \pm 2$ under normoxia), also but to a lesser extent in portal myofibroblasts ( $35 \pm 5$ vs $17 \pm 4$ ), but not in HSC-derived myofibroblasts nor in Kupffer cells. An increase in EGFR expression was induced by hypoxia also predominantly in Hepatocytes (125 \pm 12 vs $44 \pm 6)$, and to a much lesser extent in other cell types. These results demonstrate that hypoxia induces TGF- and EGFR overexpression in hepatocytes and, thereby, might act as a promoting event in liver carcinogenesis upon cirrhotic liver.
\end{abstract}

\section{Introduction}

TGF- $\alpha$ is a mitogenic factor for hepatocytes and a ligand of the EGF receptor (EGFR). TGF- $a$ can promote liver carcinogenesis, as illustrated in TGF- $\alpha$ transgenic mice, which constantly develop hepatocellular carcinoma [1]. TGF- is also overexpressed in regenerative nodules of the cirrhotic liver but the reason for this expression is unknown. Because local hypoxia is a constant feature of cirrhotic livers and hypoxia may induce TGF- $\alpha$ and EGFR expressions, the aim of this study was to determine whether the TGF-a/EGFR pathway may be affected by hypoxia in liver cells.

\section{Materials and methods \\ Cell isolation and culture}

Hepatocytes were isolated from normal Wistar rats by a method derived from Seglen [2]. Experiments were conducted in compliance with the national ethical guidelines for the care and use of laboratory animals. All experiments were performed after the approval of Institutional Animal Use and Care Committee. The animals were anesthetized with a subcutaneous injection of chlorpromazine $(2 \mathrm{mg} /$ $\mathrm{kg})$ and ketamine $(20 \mathrm{mg} / \mathrm{kg})$. The liver was perfused in situ, for 15 min with a $\mathrm{Ca}^{2+}$-free $10 \mathrm{mM}$ Hepes buffer at a flow rate of $30 \mathrm{ml}^{\mathrm{min}}{ }^{-1}$, and for 15 min with $0.025 \%$ collagenase B (Boehringer Mannheim, Meylan, France) in $\mathrm{Ca}^{2+}$-containing $10 \mathrm{mM}$ Hepes buffer at a flow rate of $20 \mathrm{ml} . \mathrm{min}^{-1}$. The hepatocytes were then separated from the connective tissue by gentle agitation in Leibovitz-15 (L15) medium (Sigma) containing $0.2 \%$ bovine serum albumin (BSA, Sigma). The resulting cell suspension was filtered through gauze, allowed to sediment for $20 \mathrm{~min}$ at $4^{\circ} \mathrm{C}$, and washed in BSA-containing L15. Hepatocytes were $80-85 \%$ pure, as assessed by characteristic cell size under phase-contrast microscopy, and cell viability exceeded $90 \%$. Hepatocytes were plated onto $100 \mathrm{~mm}$ collagen I-coated culture dishes at a density of $1.0-1.2 \times 10^{5}$ cells $/ \mathrm{cm}^{2}$ in $10 \mathrm{ml}$ William's medium $\mathrm{E}$ (GIBCO BRL, Life Technologies, Cergy-Pontoise) containing 10\% fetal bovine serum (GIBCO BRL), $5 \mathrm{mM}$ Hepes buffer, $5 \mu \mathrm{g} / \mathrm{mL}$ insulin (Novo Nordisk, Boulogne Billancourt, France), and 100,000 IU-100 mg/L penicillin-streptomycin (GIBCO BRL). After $3 \mathrm{~h}$, the medium was replaced by a serum-free medium supplemented with 1 $\mu \mathrm{M}$ hydrocortisone 21-hemisuccinate (Sigma). Medium was changed $24 \mathrm{~h}$ after plating, and then hepatocytes were subjected to hypoxic treatment. Liver myofibroblasts were obtained in culture by activation

${ }^{*}$ Correspondence to: Eduardo Schiffer, Department of Anesthesiology, Geneva University Hospitals, Switzerland, Tel: (41) 795532 069, Fax: (41) 2237276 90; E-mail: eduardo.schiffer@hcuge.ch

key words: TGF- $\alpha$, EGFR, hypoxia, carcinogenesis

Received: July 02, 2019; Accepted: July 16, 2019; Published: July 19, 2019 
of hepatic stellate cells HSC (HSC), and by outgrowth of portal myofibroblasts from bile duct segments. Hepatic stellate cells (HSC) were isolated by an established method [3] with modifications [4]. The purity of HSC isolates was higher than $99 \%$, as assessed by fluorescence of retinoid-containing vacuoles under ultraviolet excitation, and cell viability exceeded $90 \%$, as tested by erythrosine exclusion. Portal myofibroblasts were obtained as previously described [5]. HSC and portal myofibroblasts were grown on uncoated plastic in $75 \mathrm{~cm}^{2}$ flasks until confluence in DMEM (Sigma), containing 1\% penicillin/ streptomycin, $1 \%$ Hepes and $10 \%$ fetal bovine serum. The cells were maintained at $37^{\circ} \mathrm{C}$, under air/ $\mathrm{CO}_{2} 95 \% / 5 \%$. Medium was changed 24 hours after plating, and every 48 hours thereafter until confluence. Liver myofibroblasts were used within passages 3 and 5. Cultures were serum-starved just before incubation under hypoxic conditions. Kupffer cells were isolated from liver cell suspension and separated by density gradient centrifugation through $8.2 \%$ Nycodenz (Sigma) interface. Cells were washed in $25 \mathrm{~mL}$ MEM-E at $500 \mathrm{~g}$ for $7 \mathrm{~min}$, suspended in Medium 199 supplemented with 20\% serum, and plated in $60-\mathrm{mm}$ uncoated plastic tissue culture dishes at a concentration of $4-5 \times 10^{6}$ cells $/ \mathrm{mL}$ [3]. After $20 \mathrm{~min}$, nonadherent cells and residual serum were washed off the monolayer with L-15 salts and then replaced with fresh medium containing $20 \%$ serum [6]. Twenty-four hours later the culture was incubated for $3 \mathrm{~min}$ at $37^{\circ} \mathrm{C}$ with L-15 salts containing $0.5 \%$ trypsin and $0.02 \%$ EDTA. EDTA/trypsinized cells were removed by gently aspirating the monolayer with a sterile pipet and the culture was continued by addition of fresh medium containing $20 \%$ serum and then Kuppfer cells were subjected to hypoxic treatment.

\section{Cell hypoxia}

Hypoxic condition was achieved using AnaeroGen system (Oxoid, Dardilly, France), which catalytically reduces oxygen concentration to less than $1 \%$ within 30 minutes. Culture dishes were placed into a 2.51 airtight jar with an AnaeroGen sachet, and the lid was closed immediately. The jar was then incubated at $37^{\circ} \mathrm{C}$ until opening. After a designated time period, the jar was opened, and the cells were immediately lysed in order to extract RNAs and proteins. Controls included parallel cultures in which cells were subjected to normoxia ( $21 \%$ oxygen tension). In preliminary experiments, we defined durations of hypoxia that were noncytotoxic in cultures of hepatocytes or Kupffer cells ( $4 \mathrm{~h}$ hypoxia), or of HSC-derived or portal myofibroblasts $(24 \mathrm{~h}$ hypoxia), as assessed by the release of LDH activity in the medium.

\section{Reverse-transcription and real time polymerase chain reaction}

Total RNA was extracted from cells, using RNeasy Mini kit (Qiagen). Complementary DNA was synthesized from total RNA $(5 \mu \mathrm{g})$, using the Moloney Murine Leukemia Virus (MMLV) reverse transcriptase (Life Technologies) and $\mathrm{pd}(\mathrm{N}){ }_{6}$ primers (Pharmacia Biotech). Quantitative real-time polymerase chain reaction was performed using the Sybr Green PCR Core Reagents Kit (PE Applied Biosystems) on a PE Applied Biosystems 7700 Sequence Detector [4]. The primers were designed according to published rat cDNA sequences in Genbank database, using the Primer Express software v1.5 (PE Applied Biosystems) within the calibrated PCR products: VEGF Forward 5'CGTCTACCAGCGCAGCTATTG3', Reverse 5'GCACACAGGACGGCTTGAA3' as previously described (6); TGF- $\alpha$ Forward 5'TCAGTATCGGGCATCCATGTT3', Reverse 5'CCATCCCCACAGCCTTACTTT3'; EGFR Forward 5'GATCACGGCTCGTGTGTCC3', Reverse 5'ATGCCTATGCCATTGCAAACT3'; 18 S Forward 5'GAGCGAAAGCATTTGCCAAG3', Reverse 5'GGCATCGTTTATGGTCGGAA3'. In all reactions, $200 \mathrm{nM}$ of each target forward and reverse primers were used and 50nM of each $18 \mathrm{~S}$ forward and reverse primers. For each target (VEGF, TGF- $₫$ or EGFR), a PCR product was generated, sequenced, purified and calibrated as a number of copies: dilutions from $10^{2}$ to $10^{7}$ copies were used as a scale of quantification. The mRNA levels of target genes were normalized for those of $18 \mathrm{~S}$ RNA.

\section{Statistical analysis}

The Mann-Whitney $\mathrm{U}$ test was used to compare mean values between two groups. The Kruskall-Wallis test was used to compare mean values between more than two groups. The calculation of Spearman's rank correlation coefficient was used to assess the relationship between quantitative parameters. Data are expressed as means \pm SEM. All reported $P$-values are two-sided, and a $P$-value $<.05$ was considered statistically significant.

\section{Results}

Under normoxia, the expression of TGF- $\alpha$ was significantly higher in hepatocytes than in the non-parenchymal cells under study $(\sim 1.7-$ fold, figure 1, upper panel). EGFR transcripts were also more abundant in hepatocytes than in myofibroblasts $(\sim 3$-fold $)$ or in Kupffer cells ( 22-fold, figure 1, middle panel). Hypoxia induced an increase in VEGF mRNA to a similar extent in all cell types (Figure 1, lower panel). By contrast, hypoxia caused an increase in TGF- $\alpha$ transcripts mainly in hepatocytes (112 \pm 7 vs $32 \pm 2$ under normoxia), also but to a lesser extent in portal myofibroblasts ( $35 \pm 5 \mathrm{vs} 17 \pm 4$, Figure 1, upper panel), but not in HSC-derived myofibroblasts nor in Kupffer cells. An increase in EGFR expression was induced by hypoxia also predominantly in hepatocytes (125 \pm 12 vs $44 \pm 6$, figure 1, middle panel), and to a much lesser extent in other cell types (Figure 1, middle panel).

\section{Discussion and conclusion}

Cellular responses to low oxygen tension are primarily mediated by the hypoxia inducible factors (HIFs) [7,8]. Two oxygen labile subunits (HIF-1 $\alpha$ and HIF-2 $\alpha$ ) have been identified as the sensors that are coopted to mediate adaptive transcription changes involved in tumour growth pathways $[9,10]$. Well-characterized tumour promoting functions of both HIF- $1 \alpha$ and HIF- $2 \alpha$ include expression of growth factors promoting proliferation (TGF- $\alpha$ ) [11] as well as angiogenesis (VEGF) [10,12]. Furthermore, studies have shown that lifting of hypoxia would decrease the expression of HIF- $\alpha$ thus inhibiting angiogenesis and tumour growth [10].

TGF- $\alpha$ is a known ligand to EGFR, which is overexpressed as result of HIF- $2 \alpha$ activation [12]. The EGFR pathway is basically implicated in hepatocarcinoma emergence [13] and represents a target for antitumoral therapy (tyrosine kinase inhibitors) [14,15].

Our results show that hypoxia stimulates to a similar extent, the expression of EGFR, TGF- $\alpha$ and VEGF, in hepatocytes. By contrast, in HSC-derived myofibroblasts, hypoxia induced the expression of VEGF, but not that of TGF- $\alpha$ or EGFR. The central role of liver myofibroblasts in hypoxia-induced angiogenesis during hepatic wound healing has already been shown by Corpechot et al. [16]. Hepatic angiogenesis can be triggered not only by hypoxia, but also by a chronic pseudohypoxic state mediated by the accumulation of HIF-1 $\alpha$ in HSC [17].

Kupffer cells responded to hypoxia by overexpressing TGF- $\alpha$ expression whereas portal myofibroblasts showed an increase in the expression of all three genes, TGF- $\alpha$, EGFR and VEGF, but in lesser proportion compared to hepatocytes. 
TGF $-\alpha$

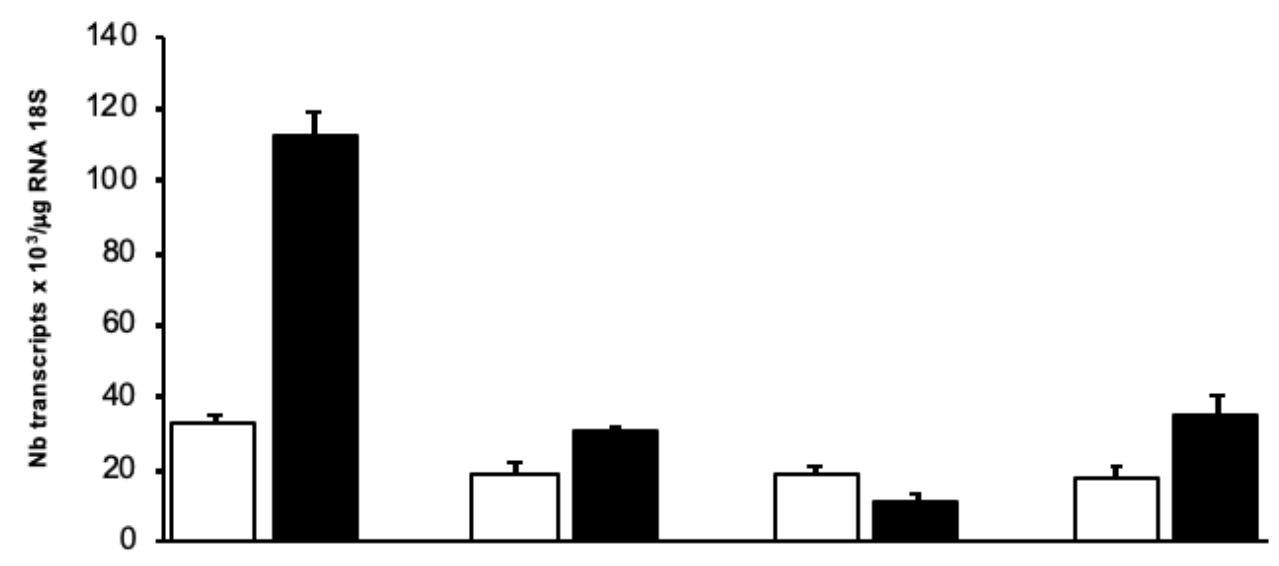

EGF-R
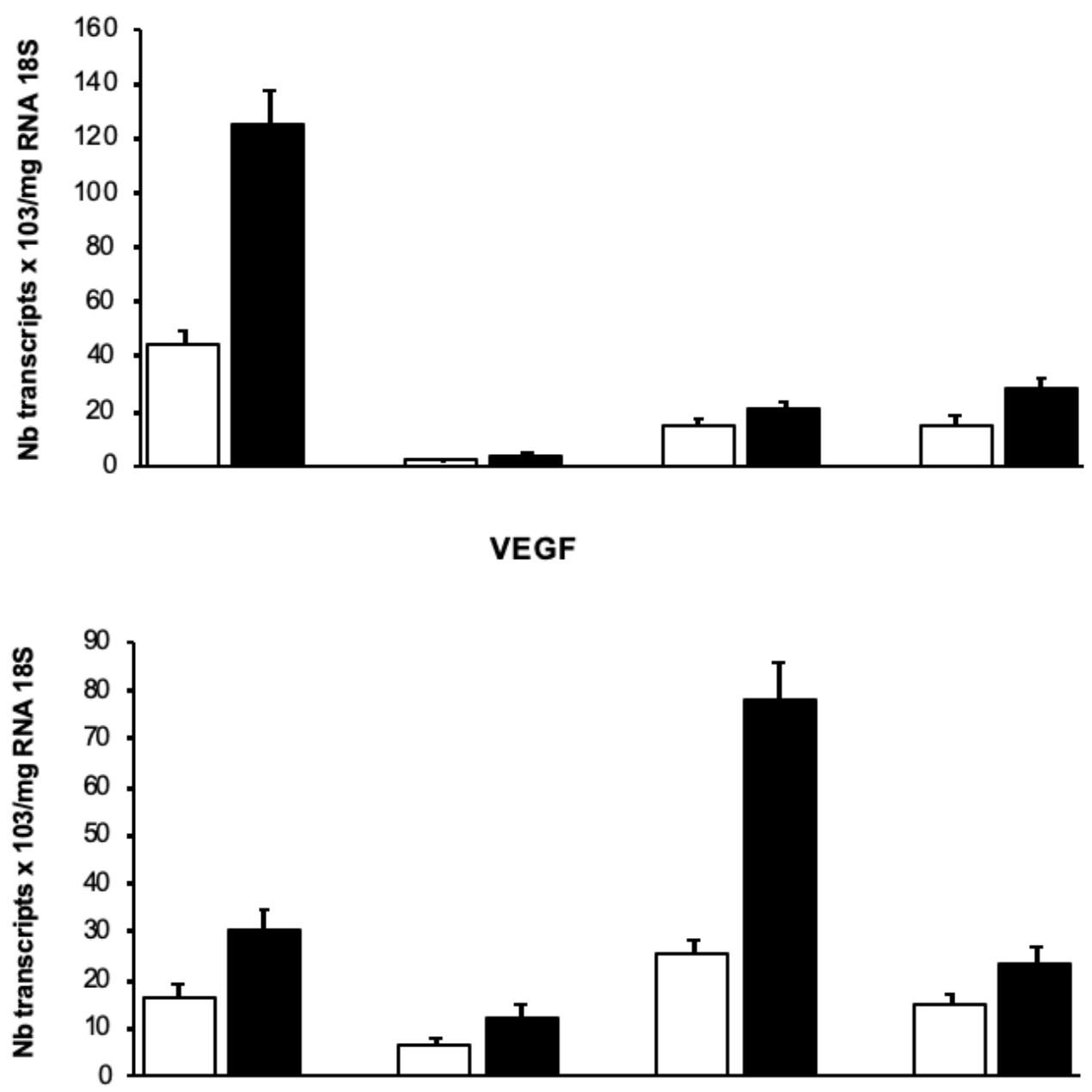

Figure 1. Response of the different liver cell types to hypoxia. Hepatocytes, Kupffer cells (KF), hepatic stellate cell-derived myofibroblasts (HSC-MF), and portal myofibroblasts (PMF), in culture, were maintained in normoxia $(\square)$ or exposed to hypoxia ( $(\mathbf{)})$, and then subjected to TGF- $\alpha$, EGFR and VEGF mRNA quantification by reverse-transcription real-time polymerase chain reaction. $* P$ value $<0.01$, between hypoxia and normoxia 
In conclusion, the present study provides further evidence to indicate that hepatocellular hypoxia enhances both angiogenesis and cell proliferation and that different liver cell types are implicated in growth factors pathways which are implicated in hypoxia-related cell proliferation. We suggest that hypoxia-induced TGF- $a$ and EGFR overexpression in hepatocytes might act as a promoting event in liver carcinogenesis in cirrhosis and could be a potential target for liver cancer prevention and therapy.

\section{Acknowledgement}

We thank Professor Martin Tramèr (Hôpital Cantonal Universitaire, Geneva, Switzerland) for providing financial support (Fonds de Service APSI).

\section{Statement of ethics}

Experiments were conducted in compliance with the national ethical guidelines for the care and use of laboratory animals. All experiments were performed after the approval of Institutional Animal Use and Care Committee. No human subjects were submitted to any experimental testing.

\section{Funding sources}

Funding for the study was provided by the Anesthesiology Departmental fund in the university hospital of Geneva.

\section{References}

1. Lee GH, Merlino G, Fausto N (1992) Development of liver tumors in transforming growth factor alpha transgenic mice. Cancer Res 52: 5162-5170. [Crossref]

2. Seglen PO (1976) Preparation of isolated rat liver cells. Methods Cell Biol 13: 29-83. [Crossref]

3. Friedman SL, Roll FR (1987) Isolation and Culture of Hepatic Lipocytes, Kuppfer Cells, and Sinusoidal Endothelial Cells by Density Gradient Centrifugation with Stractan. Anal Biochem 161: 207-218. [Crossref]

4. Kinnman N, Hultcrantz R, Barbu V, Rey C, Wendum D, et al. (2000) PDGF-mediated chemoattraction of hepatic stellate cells by bile duct segments in cholestatic liver injury. Lab Invest 80: 697-707. [Crossref]
5. El Mourabit H, Loeuillard E, Lemoinne S, Cadoret A, Housset C (2016) Culture Model of Rat Portal Myofibroblasts. Front Physiol 7: 120. [Crossref]

6. Corpechot C, Barbu V, Wendum D, Chignard N, Housset C, et al. (2002) Hepatocyte growth factor and c-Met inhibition by hepatic cell hypoxia: a potential mechanism for liver regeneration failure in experimental cirrhosis. Am J Pathol 160: 613-620. [Crossref]

7. Semenza GL (2012) Hypoxia-inducible factors in physiology and medicine. Cell 148 399-408. [Crossref]

8. Dzhalilova DS, Diatroptov ME, Tsvetkov IS, Makarova OV, Kuznetsov SL (2018) Expression of Hif-1a, Nf-?b, and Vegf Genes in the Liver and Blood Serum Levels of HIF-1a, Erythropoietin, VEGF, TGF- 3 , 8-Isoprostane, and Corticosterone in Wistar Rats with High and Low Resistance to Hypoxia. Bull Exp Biol Med 165: 781-785. [Crossref]

9. Qiu B, Simon MC (2015) Oncogenes strike a balance between cellular growth and homeostasis. Semin Cell Dev Biol 43: 3-10. [Crossref]

10. Lin S, Zhu B, Huang G, Zeng Q, Wang C (2019) Microvesicles derived from human bone marrow mesenchymal stem cells promote U2OS cell growth under hypoxia: the role of PI3K/AKT and HIF-1a. Hum Cell 32: 64-74. [Crossref]

11. Keith B, Johnson RS, Simon MC (2011) HIF1alpha and HIF2alpha: sibling rivalry in hypoxic tumour growth and progression. Nat Rev Cancer 12: 9-22. [Crossref]

12. Gunaratnam L, Morley M, Franovic A, de Paulsen N, Mekhail K, et al. (2003) Hypoxia inducible factor activates the transforming growth factor-alpha/epidermal growth factor receptor growth stimulatory pathway in VHL(-/-) renal cell carcinoma cells. $J$ Biol Chem 278: 44966-44974. [Crossref]

13. Schiffer E, Housset C, Cacheux W, Wendum D, Desbois-Mouthon C, et al. (2005) Gefitinib, an EGFR inhibitor, prevents hepatocellular carcinoma development in the rat liver with cirrhosis. Hepatology 41: 307-314. [Crossref]

14. Bocca C, Novo E, Miglietta A, Parola M (2015) Angiogenesis and Fibrogenesis in Chronic Liver Diseases. Cell Mol Gastroenterol Hepatol 1: 477-488. [Crossref]

15. Jindal A, Thadi A, Shailubhai K (2019) Hepatocellular Carcinoma: Etiology and Current and Future Drugs. J Clin Exp Hepatol 9: 221-232. [Crossref]

16. Corpechot C, Barbu V, Wendum D, Kinnman N, Rey C, et al. (2002) Hypoxia-induced VEGF and collagen I expressions are associated with angiogenesis and fibrogenesis in experimental cirrhosis. Hepatology 35: 1010-1021. [Crossref]

17. Ma H, Xie L, Zhang L, Yin X, Jiang H, et al. (2018) Activated hepatic stellate cells promote epithelial-to-mesenchymal transition in hepatocellular carcinoma through transglutaminase 2-induced pseudohypoxia. Commun Biol 1: 168. [Crossref]

Copyright: (2019 Zambreg I. This is an open-access article distributed under the terms of the Creative Commons Attribution License, which permits unrestricted use, distribution, and reproduction in any medium, provided the original author and source are credited. 